\title{
Kinetics and Mechanism of Electron Transfer to Manganese(VII) by Fluorene and Its Halogenated Derivatives in Neutral Organic Medium
}

\author{
Ahmed Fawzy, ${ }^{1,2, ~}$, Rabab J. Jassas ${ }^{1}$, Saleh A. Ahmed ${ }^{1,2}$, Rami J. Obaid ${ }^{1}$, Ishaq A. Zaafarany ${ }^{1}$ \\ ${ }^{1}$ Chemistry Department, Faculty of Applied Science, Umm Al-Qura University, Makkah, Saudi Arabia \\ ${ }^{2}$ Chemistry Department, Faculty of Science, Assiut University, Assiut, Egypt
}

Email address:

afsaad13@yahoo.com (A. Fawzy), rabab-j@hotmail.com (R. J. Jassas), saleh_63@hotmail.com (S. A. Ahmed), rjobaid@uqu.edu.sa (R. J. Obaid), iazaafarany@uqu.edu.sa (I. A. Zaafarany)

${ }^{*}$ Corresponding author

\section{To cite this article:}

Ahmed Fawzy, Rabab J. Jassas, Saleh A. Ahmed, Rami J. Obaid, Ishaq A. Zaafarany. Kinetics and Mechanism of Electron Transfer to Manganese(VII) by Fluorene and Its Halogenated Derivatives in Neutral Organic Medium. Modern Chemistry.

Vol. 4, No. 4, 2016, pp. 38-44.doi: 10.11648/j.mc.20160404.11

Received: September 10, 2016; Accepted: October 10, 2016; Published: November 1, 2016

\begin{abstract}
The kinetics of oxidation of fluorene $(\mathrm{Fl})$ and its halogenated derivatives, namely, 2,7-dichlorofluorene $(\mathrm{Fl}-\mathrm{Cl})$, 2,7-dibromofluorene (Fl-Br) and 2,7-diiodofluorene (Fl-I), by permanganate ion in neutral organic medium in the presence of phosphate buffer solution has been investigated at a constant temperature of $25^{\circ} \mathrm{C}$. The progresses of the reactions were followed spectrophotometrically. The stoichiometry of the reactions was found to be $3: 4$ (fluorene: permanganate). The oxidation reactions exhibited a first order dependence in [permanganate] and less than unit order dependences with respect to fluorenes concentrations. Under comparable experimental conditions, the order of the oxidation rate of the fluorene derivatives was: Fl-Cl $>$ Fl $>$ Fl-I $>$ Fl-Br. The final oxidation products of fluorene derivatives were identified by GC/MS, FT-IR and chemical tools as the corresponding ketones (9H-fluorenone derivatives). The proposed oxidation mechanism involves formation of 1:1 intermediate complexes between fluorene derivatives and permanganate ion in pre-equilibrium step. The ratelaw expression was deduced. The reactions constants involved in the different steps of the mechanism were evaluated. The activation parameters associated with the second order rate constants were calculated and discussed.
\end{abstract}

Keywords: Fluorenes, Neutral Organic Medium, Oxidation, Permanganate, Kinetics, Mechanism

\section{Introduction}

Oxidation reactions are very important in nature and are regarded as key transformations in organic synthesis. Fluorene is a unique class of are polycyclic aromatic hydrocarbons (PAHs) exist in the fossil fuels and petrogenic sources are among products from the burning of gasoline [1, 2]. Fluorene has a large list of significant applications [3-10] as dye-sensitized solar cells [3], polymer light-emitting diodes $[4,5]$ and electro-emitting materials [6]. Moreover, fluorene and its derivatives are considered as effective and pronounced precursors for the synthesis of photochromic di and tetrahydroindolizines [11-14].

Permanganate ion is an efficient oxidant in acid, neutral and alkaline media [15-28] which still remains as one of the most important, eco-friendly and powerful multi-electron oxidants employed in the kinetic studies [29]. The mechanism of oxidation by this multivalent oxidant depends not only on the substrate but also on the medium used for the study. During oxidation by permanganate ion, it is evident that the $\mathrm{Mn}$ (VII) species in permanganate is reduced to various oxidation states in different media.

The present study deals with the oxidative behavior of permanganate ion with fluorene and its halogenated derivatives in neutral organic medium to establish the optimum conditions affecting oxidation of such organic 
substrates and to elucidate a plausible oxidation mechanism on the basis of the obtained kinetic and spectral results.

\section{Experimental}

\subsection{Materials}

All chemicals employed in this investigation were of Aldrich grades. Fluorene and its derivatives, 2,7dichloroflourene, 2,7-dibromoflourene and 2,7-diiodoflourene were prepared according to the described procedures with some modifications [30, 31]. The synthesized fluorene derivatives were confirmed by both spectroscopic and analytical tools. All solvents used were of spectroscopic grade and used without further purifications. The solvents used were checked for the absence of absorbing or any fluorescent impurities. A fresh solution of potassium permanganate was prepared and standardized as reported [32]. Phosphate buffer solution was used to maintain the neutral medium.

\subsection{Kinetic Measurements}

The kinetic runs were followed under pseudo-first order conditions where fluorene substrates (abbreviated by F) were exist in large excess over that of potassium permanganate. Initiation of the reactions were done by mixing the formerly thermostatted solutions of permanganate and substrate that also contained the required amounts of phosphate buffer solution. The courses of the reactions were followed up to not less than two half-lives by monitoring the diminish in the absorbance of permanganate as a function of time at its absorption maximum $(\lambda=525 \mathrm{~nm})$, whereas the other constituents of the reaction mixtures did not absorb considerably at the determined wavelength. Fluorene derivatives were confirmed by both spectroscopic and analytical tools. The melting points of fluorene derivatives were recorded using a Gallenkamp melting point apparatus. NMR was recorded on a Bruker Advance $400 \mathrm{MHz}$ with $\mathrm{CDCl}_{3}$ and DMSO as solvents with tetramethylsilane (TMS) as the internal reference. GC-Mass spectra were recorded on a Shimadzu GCMS-QP1000 EX mass spectrometer at $70 \mathrm{eV}$. The absorption measurements were done in a temperature-controlled Shimadzu UV-VISNIR-3600 double-beam spectrophotometer.

First order plots of $\ln ($ absorbance) versus time were recorded to be straight lines up to at least $70 \%$ of the reactions completion and the observed first order rate constants $\left(k_{\text {obs }}\right)$ were calculated as the gradients of such plots. Ordinary values of at least two independent determinations of the rate constants were taken for the analysis. The rate constants were reproducible to within $4 \%$. The orders of the reactions with respect to the reactants were determined from the slopes of the $\log k_{\mathrm{obs}}$ versus $\log$ (concentration) plots by varying the concentrations of substrates while keeping other conditions constant.

\section{Results}

\subsection{Reactions Stoichiometry and Products Analysis}

The stoichiometry of the reactions was analyzed periodically by spectrophotometric technique. The results indicate consumption of four permanganate ions for three molecules of fluorene derivatives to yield the final oxidation products as shown in the following equation,<smiles>[Y4]c1ccc2c(c1)Cc1cc([X])ccc1-2</smiles>

Fluorene derivative

The above stoichiometric equation is in good consistent with the results of products analysis as confirmed by the head-space GC/MS, FT-IR spectra and chemical tools as reported earlier $[33,34]$.

\subsection{Time-Resolved Spectra}

Time-resolved spectra throughout the oxidation of fluorene and its halogenated derivatives $(\mathrm{F})$ by permanganate ion in neutral organic medium in the presence of phosphate buffer solution are shown in Figure 1(a-d). The main characteristic feature observed from the figure was the gradual disappearance of permanganate band at $\lambda=525 \mathrm{~nm}$. In some cases, there were changes in the absorption spectra of permanganate ion with appearance of isosbestic points in the spectra.

\subsection{Rates Dependence on Permanganate Concentration}

The effect of permanganate concentration on the oxidation rates of fluorene and its halogenated derivatives was studied by varying its concentration in the range of $(1.0-10.0) \times 10^{-4}$ mol dm$~^{-3}$ at fixed fluorenes concentration and temperature. The order with respect to $\left[\mathrm{MnO}_{4}^{-}\right]$was found to be unity, as plots of $\ln$ (absorbance) versus time were linear up to about $70 \%$ of the reactions completion. The first order dependence of the reactions on $\left[\mathrm{MnO}_{4}^{-}\right]$was also confirmed by the nonvariation of the observed first order rate constant $\left(k_{\mathrm{obs}}\right)$ at various $\left[\mathrm{MnO}_{4}^{-}\right]$while keeping others constant.

\subsection{Rates Dependence on Fluorenes Concentrations}

The oxidation rates were examined at different initial concentrations of the fluorenes reductants keeping other conditions constant. It was found that the oxidation rates increased with increasing the concentration of fluorenes as listed in Table 1. The plots of $k_{\text {obs }}$ versus [F] were found to be linear with positive intercepts on the $k_{\mathrm{obs}}$ axes as shown in Figure 2 suggesting that the orders with respect to fluorenes 
concentrations were less than unity.
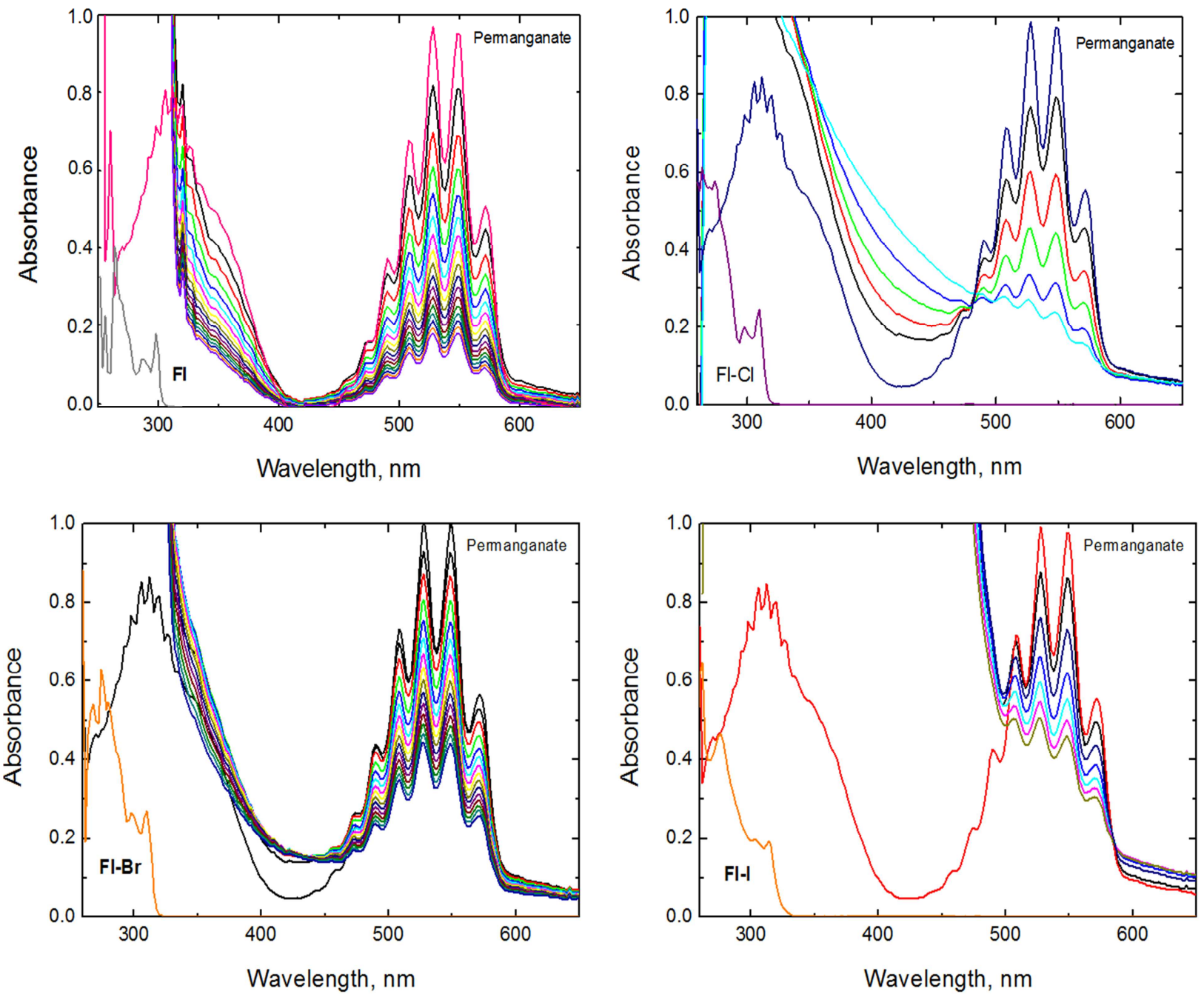

Figure 1. Time-resolved spectra throughout oxidation of fluorene and its halogenated derivatives by permanganate ion in neutral medium. $[\mathrm{F}]=6.0 \times 10^{-3}$, $\left[\mathrm{MnO}_{4}^{-}\right]=4.0 \times 10^{-4} \mathrm{~mol} \mathrm{dm}^{-3}$ at $25^{\circ} \mathrm{C}$. Scanning time intervals $=2.0 \mathrm{~min}$.

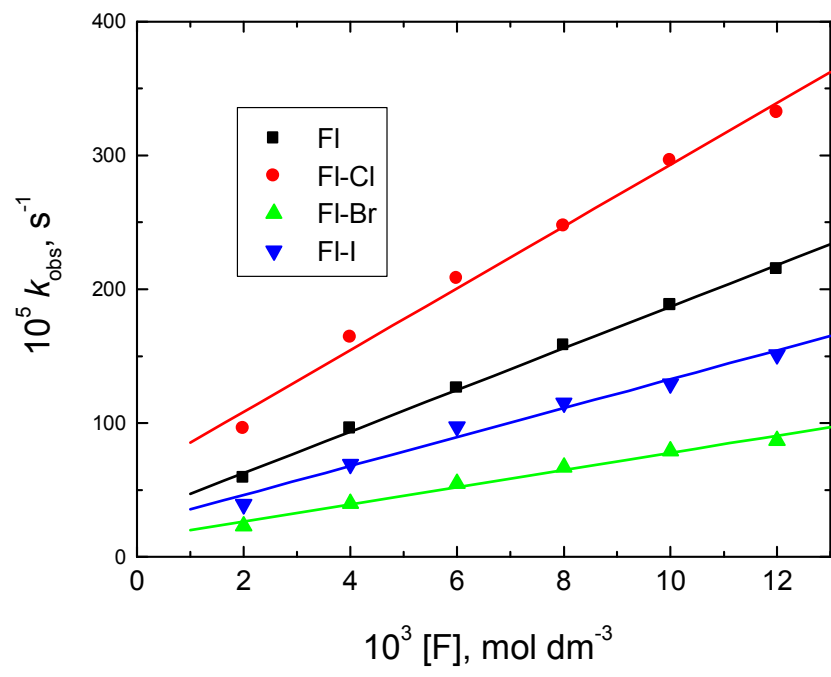

Figure 2. Plots of the observed-first order rate constants $\left(k_{o b s}\right)$ versus fluorenes concentrations in the oxidation of fluorene and its halogenated derivatives by permanganate ion in neutral medium at $25^{\circ} \mathrm{C}$.
Table 1. Effect of fluorenes concentrations on the observed-first order rate constants $\left(k_{o b s}\right)$ in the oxidation of fluorene and its halogenated derivatives by permanganate ion in neutral medium at $25^{\circ} \mathrm{C}$.

\begin{tabular}{|c|c|c|c|c|}
\hline \multirow{2}{*}{$\begin{array}{l}10^{3}[\mathrm{~F}] \\
\left(\mathrm{mol} \mathrm{dm}^{-3}\right)\end{array}$} & \multicolumn{4}{|c|}{$10^{5} k_{\text {obs }}\left(\mathrm{s}^{-1}\right)$} \\
\hline & Fl & Fl-Cl & Fl-Br & Fl-I \\
\hline 2.0 & 59 & 96 & 23 & 39 \\
\hline 4.0 & 96 & 164 & 40 & 69 \\
\hline 6.0 & 126 & 208 & 55 & 97 \\
\hline 8.0 & 158 & 247 & 67 & 115 \\
\hline 10.0 & 188 & 296 & 79 & 129 \\
\hline 12.0 & 215 & 332 & 87 & 151 \\
\hline
\end{tabular}

Experimental error $\pm 3 \%$

\subsection{Effect of Temperature}

The rates of oxidation were measured at four different temperatures namely, $15,25,35$ and $45^{\circ} \mathrm{C}$ at constant concentrations of the reactants and other conditions being 
constant. The results indicate that the rate constants increased with rise in temperature. The activation parameters of the second order rate constant $\left(k_{2}\right)$ are calculated using Eyring and Arrhenius equations and are listed in Table 2.

Table 2. Activation parameters of the second order rate constant, $k_{2}$, in the oxidations of fluorene and its halogenated derivatives by permanganate ion in neutral medium.

\begin{tabular}{|c|c|c|c|c|}
\hline Substrate & $\begin{array}{l}\Delta \boldsymbol{S}^{\ddagger} \\
\mathbf{J} \mathbf{m o l}^{-1} \mathbf{K}^{-1}\end{array}$ & $\begin{array}{l}\Delta H^{\ddagger} \\
\mathrm{kJ} \mathrm{mol}^{-1}\end{array}$ & $\begin{array}{l}\Delta G_{298}^{\ddagger} \\
\mathrm{kJ} \mathrm{mol}^{-1}\end{array}$ & $\begin{array}{l}E_{\mathrm{a}}{ }^{\neq} \\
\mathrm{kJ} \mathrm{mol}^{-1}\end{array}$ \\
\hline Fl & -89.08 & 47.12 & 73.66 & 50.71 \\
\hline Fl-Cl & -107.24 & 42.87 & 74.82 & 44.99 \\
\hline Fl-Br & -91.77 & 55.79 & 83.13 & 58.09 \\
\hline Fl-I & -78.98 & 51.04 & 74.58 & 53.91 \\
\hline
\end{tabular}

Experimental error $\pm 4 \%$

\subsection{Free Radical Test}

The involvement of free radicals in the oxidation reactions was examined by addition of known quantities of acrylonitrile monomer to the reactions mixtures and was kept in inert atmosphere for about 6 hours at room temperature. When the reactions mixtures were diluted with methanol, heavy white precipitates were formed suggesting that there was participation of free radicals in the present oxidation reactions. When the experiments were repeated in the absence of the fluorene derivatives under similar conditions, the tests were negative. This indicates that the reactions were routed through free radical paths.

\section{Discussion}

Permanganate ion in various media provides excellent results when used in oxidation processes. In the permanganate ion, manganese has an oxidation state of VII. It is stable in neutral or slightly alkaline media, but, in a strongly alkaline medium, [29] it disproportionates or reacts with hydroxide ion to form manganese(V) (hypomanganate) or manganese(VI) (manganate). Manganese(VII) is reduced to $\mathrm{Mn}(\mathrm{II})$ during oxidation processes via many manganese species having different oxidation states such as $\mathrm{Mn}(\mathrm{VI})$, $\mathrm{Mn}(\mathrm{V}), \mathrm{Mn}(\mathrm{IV})$ and $\mathrm{Mn}(\mathrm{III})$. The appearance of these intermediate oxidation states depends upon various reaction conditions and the type of substrate. In neutral or slightly alkaline solutions, permanganate used as a powerful oxidizing agent $\left(E_{\mathrm{o}}=+1.23 \mathrm{~V}\right)$ according to the equation:

$$
\mathrm{MnO} 4-+2 \mathrm{H} 2 \mathrm{O}+3 \mathrm{e}=\mathrm{MnO} 2+4 \mathrm{OH}-
$$

On the other hand, oxidation reactions involving permanganate ion as an oxidant are suggested [15-23] to proceed through intermediate complex formation between oxidant and substrate especially in neutral and alkaline media. The formation of manganate(VI) and/or hypomanganate $(\mathrm{V})$ short-lived intermediates may be confirmed by the change in the color of the solution mixture as the reaction proceeded from purple-pink, $\mathrm{Mn}(\mathrm{VII})$, to blue, $\mathrm{Mn}(\mathrm{V})$, to green, $\mathrm{Mn}(\mathrm{VI})$. As the reactions proceed, a yellow turbidity slowly develops and on prolonged standing, the solution turns to colorless with a brown colloidal precipitate, $\mathrm{Mn}^{\mathrm{IV}} \mathrm{O}_{2}$. The failure to detect $\mathrm{Mn}(\mathrm{V})$, absence of an absorption maximum around $\lambda=700 \mathrm{~nm}$, may be interpreted by its extreme short lifetime and undergoing a rapid disproportionation [20,35].

The present reactions between fluorene derivatives $(\mathrm{F})$ and permanganate ion in neutral organic medium have a stoichiometry of 3:4 (fluorene: permanganate) with a firstorder dependence on $\left[\mathrm{MnO}_{4}^{-}\right]$and less than unit order dependences with respect to $[\mathrm{F}]$. The less than unit order dependences with respect to fluorenes concentrations suggests formation of intermediate complexes between fluorenes and permanganate ion in pre-equilibrium step. Spectral evidence for complexes formation was obtained from the UV-Vis spectra (Figure 1) where there were changes in the absorption spectra of permanganate ion with appearance of isosbestic points in the spectra. Another support for complexes formation is the kinetic evidence as the plots of $1 / k_{\text {obs }}$ versus $1 /[\mathrm{F}]$ were found to be linear with positive intercepts on $1 /[\mathrm{F}]$ axes as shown in Figure 3, similar to the well-known Michaelis-Menten mechanism for enzyme-substrate reactions [36].

Based on the experimental results, permanganate ion is suggested to react with one mole of fluorine substrate in a pre-equilibrium step to give an intermediate complex (C). The cleavage of such complex leads to the formation of a free radical derived from fluorine substrate and an intermediate $\mathrm{Mn}(\mathrm{VI})$ species. Such intermediate is rapidly attacked by manganate(VI) ion to yield the corresponding secondary alcohol and $\mathrm{Mn}(\mathrm{V})$ species. In a further fast step, the intermediate $\mathrm{Mn}(\mathrm{V})$ being very active and unstable reacts with the formed secondary alcohol to give rise to the final oxidation product of fluorine (ketone) and an intermediate $\mathrm{Mn}$ (III) species. This step is followed by reactions between fluorenes and permanganate ions giving other oxidation products of fluorenes, and finally a reaction between $\mathrm{Mn}(\mathrm{V})$ and $\mathrm{Mn}(\mathrm{III})$ species was led to formation of $\mathrm{Mn}^{\mathrm{IV}} \mathrm{O}_{2}$ as the final oxidation product of permanganate, satisfying the observed reactions stoichiometry. The proposed mechanism is illustrated in Scheme 1.

The obtained large negative values of $\Delta S^{\neq}$(Table 2) suggests that the more plausible mechanism is one-electron transfer of inner-sphere nature [36-38]. Also, the large negative values of $\Delta S^{\ddagger}$ indicate that there is a decrease in the randomness during the oxidation process. This leads to the formation of compacted intermediate complexes and such activated complexes are more ordered than the reactants due to loss of degree of freedom. On the other hand, the positive value of $\Delta H^{\neq}$indicates that the complexes formation is endothermic. Also, the large positive value of $\Delta G^{\neq}$suggests enhanced formation of the intermediates with increasing temperature as well as to the non-spontaneities of the complexes formation. 


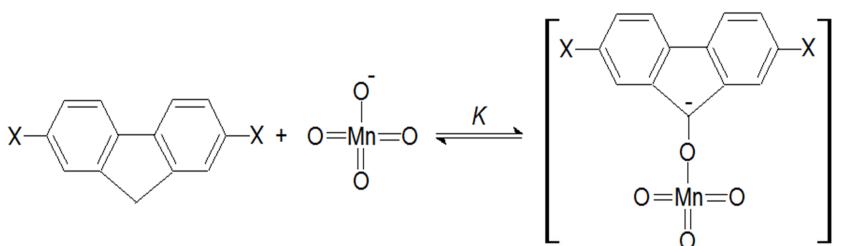

(C)

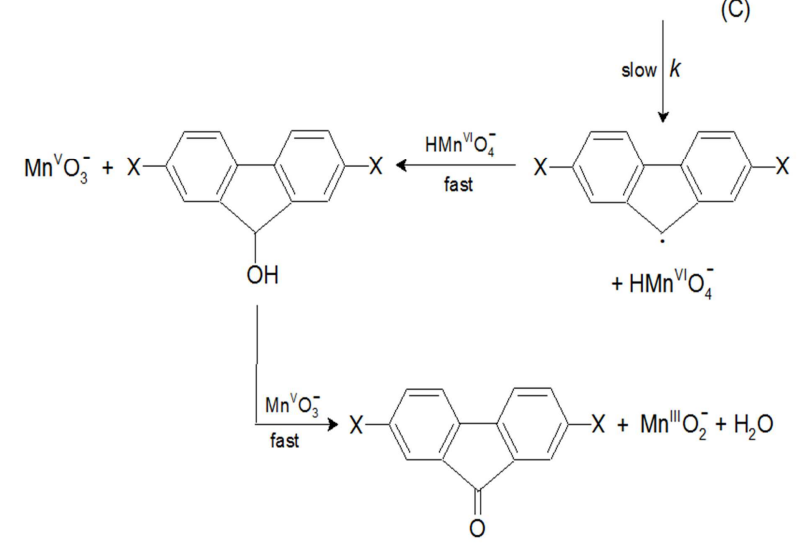

$\mathrm{Mn}^{\mathrm{V}} \mathrm{O}_{3}^{-}+\mathrm{Mn}^{\mathrm{III}} \mathrm{O}_{2}^{-}+\mathrm{H}_{2} \mathrm{O}=2 \mathrm{Mn}^{\mathrm{IV}} \mathrm{O}_{2}+2 \mathrm{OH}^{-}$

Scheme 1. Mechanism of oxidation of fluorenes by permanganate ion in neutral medium.

According to the mechanistic Scheme 1, the oxidation rate can be expressed as follows,

According to Scheme 1,

$$
\text { Rate }=\frac{-d\left[\mathrm{MnO}_{4}^{-}\right]}{d t}=k[C]
$$

Also,

$$
K=\frac{[\mathrm{C}]}{[\mathrm{F}]\left[\mathrm{MnO}_{4}^{-}\right]}
$$

Therefore,

$$
[\mathrm{C}]=K[\mathrm{~F}]\left[\mathrm{MnO}_{4}^{-}\right]
$$

Substituting Eq. (4) in Eq. (2) leads to the following equation,

$$
\text { Rate }=k K[\mathrm{~F}]\left[\mathrm{MnO}_{4}^{-}\right]
$$

The total concentration of fluorine substrate is given by,

$$
[\mathrm{F}]_{\mathrm{T}}=[\mathrm{F}]_{\mathrm{F}}+[\mathrm{C}]
$$

where $\mathrm{T}$ and $\mathrm{F}$ refer to total and free concentrations, respectively.

Therefore,

$$
[\mathrm{F}]_{\mathrm{F}}=\frac{[\mathrm{F}]_{\mathrm{T}}}{1+K\left[\mathrm{MnO}_{4}^{-}\right]}
$$

Similarly,

$$
\left[\mathrm{MnO}_{4}^{-}\right]_{\mathrm{T}}=\left[\mathrm{MnO}_{4}^{-}\right]_{\mathrm{F}}+[\mathrm{C}]
$$

$$
\left[\mathrm{MnO}_{4}^{-}\right]_{F}=\frac{\left[\mathrm{MnO}_{4}^{-}\right]_{T}}{1+K[\mathrm{~F}]}
$$

Substituting Eqs. (6) and (8) into Eq. (4), the following equation is obtained,

$$
\text { Rate }=\frac{k K[\mathrm{~F}]\left[\mathrm{MnO}_{4}^{-}\right]}{\left(1+K\left[\mathrm{MnO}_{4}^{-}\right]\right)(1+K[\mathrm{~F}])}
$$

In view of low concentration of $\left[\mathrm{MnO}_{4}{ }^{-}\right]$used, the first term in the denominator of Eq (10) approximate to unity.

Therefore, Eq. (9) becomes,

$$
\text { Rate }=\frac{k K[\mathrm{~F}]\left[\mathrm{MnO}_{4}^{-}\right]}{1+K[\mathrm{~F}]}
$$

Under pseudo-first order conditions, the rate-law can be expressed as,

$$
\text { Rate }=\frac{-d\left[\mathrm{MnO}_{4}^{-}\right]}{d t}=k_{o b s}\left[\mathrm{MnO}_{4}^{-}\right]
$$

Comparing Eqs (11) and (12), and with rearrangement the following relationship is obtained,

$$
\frac{1}{k_{\mathrm{obs}}}=\left(\frac{1}{k K}\right) \frac{1}{[\mathrm{~F}]}+\frac{1}{k}
$$

According to Eq. (12), the plots of $1 / k_{\text {obs }}$ versus $1 /[\mathrm{F}]$ (for fluorene derivatives) were found to be straight lines with positive intercepts on $1 / k_{\mathrm{obs}}$ axes as illustrated in Figure 3 satisfying the proposed mechanism. From the intercepts and slopes of such plots, the rate constant of the slow step, $k$, and the formation constant of the intermediate complexes, $K$, are determined and are listed in Table 3.

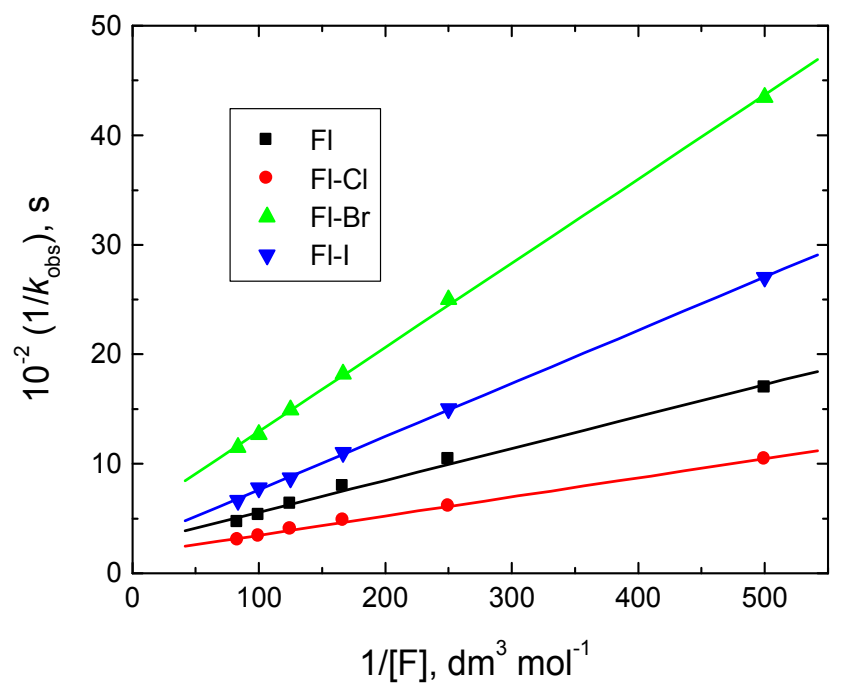

Figure 3. Plots of $1 / k_{\text {obs }}$ versus $1 /[F]$ in the oxidation of fluorene and its halogenated derivatives by permanganate ion in neutral medium at $25^{\circ} \mathrm{C}$. 
Table 3. Values of the rate constant of the slow step $(k)$ and the equilibrium constant $(K)$ in the oxidations of fluorene and its halogenated derivatives by permanganate ion in neutral medium.

\begin{tabular}{lllll}
\hline Constant & Fl & Fl-Cl & Fl-Br & Fl-I \\
\hline $\mathbf{1 0}^{\mathbf{3}} \boldsymbol{k}\left(\mathbf{s}^{-\mathbf{1}}\right)$ & 3.77 & 5.81 & 1.90 & 3.63 \\
$\boldsymbol{K}\left(\mathbf{d m}^{\mathbf{3}} \mathbf{~ m o l}^{-\mathbf{1}}\right)$ & 91.37 & 101.18 & 69.08 & 57.29 \\
\hline
\end{tabular}

Experimental error $\pm 3 \%$

\section{Conclusions}

The kinetics of oxidation of fluorene and its halogenated derivatives by permanganate ion in neutral organic medium was studied spectrophotometrically. The final oxidation products of fluorene derivatives were identified by GC/MS, FT-IR and chemical tools as the corresponding ketones $(9 \mathrm{H}-$ fluorenone derivatives). Under comparable experimental conditions, the order of the oxidation rate of the fluorene derivatives was: $\mathrm{Fl}-\mathrm{Cl}>\mathrm{Fl}>\mathrm{Fl}-\mathrm{I}>\mathrm{Fl}-\mathrm{Br}$.

\section{References}

[1] Thormann T, Rogojerov M, Jordanov B, Thulstrup EW (1999) Vibrational polarization spectroscopy of fluorene: alignment in stretched polymers and nematic liquid crystals, J. Mol. Str. 509: 93-99.

[2] Environmental contaminants encyclopedia fluorene entry July 1, 1997.

[3] Li X, Lü H, Wang S, Guo J, Li J (2011) Sensitizers of dye-sensitized solar cells, Prog. Chem., 23:569-588.

[4] Ma Z, Ding J, Cheng Y, Xie Z, Wang L, Jing X, Wang F (2011) Synthesis and characterization of red lightemitting electrophosphorescent polymers with different triplet energy main chain, Polymer, 52: 2189-2197.

[5] Wang HY, Qian Q, Lin KH, Peng B, Huang W, Liu F, Wei W (2012) Stable and good color purity white lightemitting devices based on random fluorene/spirofluorene copolymers doped with iridium complex, J. Polym. Sci. B, 50:180-188.

[6] Yang XH, Wu FI, Neher D, Chien CH, Shu CF (2008) Polyfluorene-based semiconductors combined with various periodic table elements for organic electronics, Chem. Mater., 20:1629-1635.

[7] Kucherak OA, Didier P, Mély Y, Klymchenko AS (2010) Fluorene analogues of prodan with superior fluorescence brightness and solvatochromism, J. Phys. Chem. Lett., $1: 616-620$.

[8] Cheng YJ, Yang SH, Hsu CS (2009) Synthesis of conjugated polymers for organic solar cell applications, Chem. Rev., 109: 5868-5923.

[9] Xing X, Zhang L, Liu R, Li S, Qu B, Chen Z (2012) A deep-blue emitter with electron transporting property to improve charge balance for organic light-emitting device, ACS Appl. Mater. Interf., 4:2877-2883.

[10] Pina J de, Melo JSS, Egkert A, Scherf U (2015) Unusual photophysical properties of conjugated, alternating indigofluorene copolymers, J. Mater. Chem. A, 3:6373-6381.
[11] Fromm R, Ahmed SA, Hartmann Th, Huch V, AbdelWahab AA, Dürr A (2001) Eur. J. Org. Chem., 21:40774085 .

[12] Ahmed SA, Abdel-Wahab AA, Dürr H (2003) CRC Handbook of organic photochemistry and photobiology, Horspool WM, Lenci F edn, CRC press, New York, $2^{\text {nd }}$ edn, Chapter 96, p 1.

[13] Ahmed SA, Hartmann Th, Dürr H (2008) Photochromism of dihydroindolizines: Part VIII. First holographic image recording based on di- \& tetrahydroindolizines photochromes, J. Photochem. Photobiol., 200: 50-56.

[14] Ahmed SA, Pozzo JL (2008) Photochromism of dihydroindolizines Part IX. First attempts towards efficient self-assembling organogelators based on photochromicdihydroindolizines and N-acyl-I, $\omega$-amino acid units, J. Photochem. Photobiol., 200: 57-67.

[15] Fawzy A, Ashour SS, Musleh MA (2014) Base-catalyzed oxidation of L-asparagine by alkaline permanganate and the effect of alkali-metal ion catalysts: kinetics and mechanistic approach, React. Kinet. Mech. Catal. 111: 443-460.

[16] Fawzy A, Shaaban MR (2014) Kinetic and mechanistic investigations on the oxidation of N'-heteroaryl unsymmetrical formamidines by permanganate in aqueous alkaline medium. Transition Met. Chem. 39: 379-386.

[17] Fawzy A, Zaafarany IA, Alfahemi J, Tirkistani FA (2015) Base-catalyzed oxidation of aminotriazole derivative by permanganate ion in aqueous alkaline medium: a kinetic study. Int. J. Inn. Res. Sci. Eng. Tech., 4: 6802-6814.

[18] Asghar BH, Fawzy A (2016) Kinetic, mechanistic, and spectroscopic studies of permanganate oxidation of azinylformamidines in acidic medium, with autocatalytic behavior of manganese(II). J. Saudi Chem. Soc., 20: 561-569.

[19] Fawzy A, Ashour SS, Musleh MA (2014) Kinetics and mechanism of oxidation of L-histidine by permanganate ions in sulfuric acid medium. Int. J. Chem. Kinet., 46: 370-381.

[20] Ahmed GA, Fawzy A, Hassan RM (2007) Spectrophotometric evidence for the formation of shortlived hypomanganate(V) and manganate(VI) transient species during the oxidation of $K$-carrageenan by alkaline permanganate. Carbohydr. Res., 342: 1382-1386.

[21] Zaafarany IA, Fawzy A, Ahmed GA, Ibrahim SA, Hassan RM, Takagi HD (2010) Further evidence for detection of short-lived transient hypomanganate(V) and manganate(VI) intermediates during oxidation of some sulfated polysaccharides by alkaline permanganate using conventional spectrophotometeric techniques. Carbohydr. Res., 345: 1588-1593.

[22] Hassan RM, Fawzy A, Alarifi A, Ahmed GA, Zaafarany IA, Takagi HD (2011) Base-catalyzed oxidation of some sulfated macromolecules: kinetics and mechanism of formation of intermediate complexes of short-lived manganate (VI) and/or hypomanganate (V) during oxidation of iota- and lambda-carrageenan polysaccharides by alkaline permanganate. J. Mol. Catal. A, 335: 38-45. 
[23] Hassan RM, Dahy A, Ibrahim S, Zaafarany IA, Fawzy A (2012) Oxidation of some macromolecules. Kinetics and mechanism of oxidation of methyl cellulose polysaccharide by permanganate ion in acid perchlorate solutions. Ind. Eng. Chem. Res. 51: 5424-5432.

[24] Gardner KA, Kuehnert LL, Mayer JM (1997) Hydrogen atom abstraction by permanganate: oxidations of arylalkanes in organic solvents. Inorg. Chem., 36: 20692078.

[25] Kini AK, Farokhi SA, Nandibewoor ST (2002) A comparative study of ruthenium(III) catalysed oxidation of L-leucine and L-isoleucine by alkaline permanganate. A kinetic and mechanistic approach. Transition Met. Chem., 27: 532-540.

[26] Halligudi LL, Desai SM, Mavalangi AK, Nandibewoor ST. (2000) Kinetics of the oxidative degradation of racserine by aqueous alkaline permanganate. Monatsh Chem., 131: 321-332.

[27] Verma RS, Reddy JM, Shastry VR. (1974) Kinetic study of homogeneous acid-catalyzed oxidation of certain amino-acids by potassium permanganate in moderately concentrated acidic media. J Chem Soc Perkin Trans., 124: 469-473.

[28] Mohanty B, Behera J, Acharya S, Mohanty P, Pantaik AK. Metal ion catalyzed oxidation of L-lysine by alkaline permanganate Ion-A kinetic and mechanistic approach. Chem. Sci. Trans.. 2013: 2, 51-60.

[29] Cotton FA, Wilkinson G. Advanced Inorganic Chemistry, p 747, John Wiley and Sons, New York (1980).
[30] Ahmed SA (2004) Photochromism of dihydroindolizines. III: synthesis and photochromic behavior of novel photochromic dihydroindolizines incorporating a cholesterol moiety, Monatsh. Chem., 135:1173-1181.

[31] Ahmed SA, Khairou KS, Asghar BH, Muathen HA, Nahas NMA, Al Shreef HF (2014) Photochromism of tetrahydroindolizines. Part XIV: Synthesis of cis-fixed conjugated photochromic pyridazinopyrrolo [1,2-b] isoquinolines incorporating carbon-rich linkers, Tetrahderon Lett., 55: 2190-2197.

[32] Vogel IA. (1978) A Text Book of Quantitative Inorganic Analysis. $4^{\text {th }}$ edn, p 352, ELBS, Longman.

[33] Vogel AI (1973) Text book of practical organic chemistry including quantitative organic analysis, 3rd edn, p 332, ELBS, Longman.

[34] Feigl F (1975) Spot tests in organic analysis, p 195, Elsevier, New York.

[35] Zimmerman CL. Ph D. Thesis University of Chicago (1949).

[36] Michaelis L, Menten ML (1913) The kinetics of invertase action. Biochem. Z., 49: 333-369.

[37] Hicks KW, Toppen DL, Linck RG (1972) Inner-sphere electron-transfer reactions of vanadium(II) with azidoamine complexes of cobalt(III). Inorg. Chem., 11: 310-315.

[38] Sutin N (1968) Free energies, barriers, and reactivity patterns in oxidation-reduction reactions. Acc. Chem. Res., 1: 225-231. 